IFAS Extension

\title{
Vida Saludable: Sitios Web Confiables ${ }^{1}$
}

Linda B. Bobroff y Leigh Ann Martin²

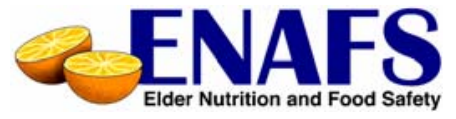

¿Sabia usted que ahora el Internet tiene mas de 2 billones de sitios Web? Podría ser difícil de creer, pero es verdad, y el número de sitios Web cada día crece más.

Desafortunadamente, no hay regulaciones que aseguren que la información encontrada es confiable. De hecho, hay muchos sitios Web que NO proveen información confiable.

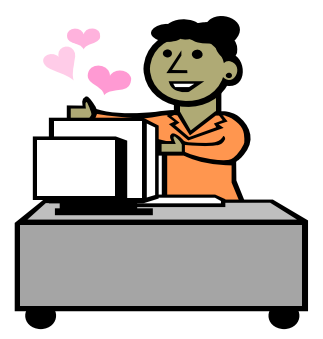

\section{¿Como puede escoger un sitio Web inteligentemente?}

Concéntrese en los sitios del gobierno y educación-busque direcciones de sitios Web (URLs) que terminen en .gov o .edu. Muchas organizaciones (sitios .org) también tienen buena información. Tenga en cuanta que los sitios comerciales (.com) pueden estar promoviendo productos o servicios, y su información podría o no podría ser confiable o arbitraria.

He aquí una lista de Fuentes de Internet confiables relacionadas con nutrición, salud, seguridad en los alimentos y recursos para personas mayores. Muchos de ellos ofrecen conexión sitios Web adicionales.

\section{Nutrición y Salud}

National Agricultural Library, U.S. Department of Agriculture: http://nutrition.gov (Información y recursos de nutrición y salud)

National Library of Medicine: http://medlineplus.gov

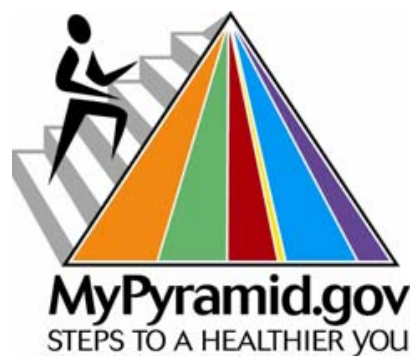
(Información de medicinas, términos médicos, directorio de proveedores y más)

U.S. Department of Agriculture: http://www.usda.gov/cnpp

(Educación nutricional para adultos y niños/jóvenes, incluyendo MyPyramid, guías de dieta, contenido nutricional en alimentos y más)

\footnotetext{
${ }^{1}$ The English version of this Spanish document is Healthy Living: Reliable Web Sites (FCS8587). Este documento, FCS8587-SPAN, pertenece a una serie del Departamento de Ciencias de la Familia, Juventud y Comunidad, Servicio de Extensión Cooperativo de la Florida, Instituto de Alimentos y Ciencias Agrícolas, Universidad de la Florida. Fecha de publicación: marzo 2000. Revisado: mayo 2007. Favor de visitar el sitio Web de EDIS en http://edis.ifas.ufl.edu.

${ }^{2}$ Linda B. Bobroff, profesora, Departamento de Ciencias de la Familia, Juventud y Comunidad, Servicio de Extensión Cooperativo de la Florida, Instituto de Alimentos y Ciencias Agrícolas, Universidad de la Florida. Traducción por Sergio Romero anteriormente con la Universidad de la Florida, Gainesville, 


\section{Seguridad en los Alimentos}

National Food Safety Database:

http://foodsafety.ifas.ufl.edu/indexNFSDB.htm

(Imprima materiales en inglés y en español)

U.S. Department of Agriculture: http://www.foodsafety.gov

(Consejos para mantener la carne y el pollo seguros)

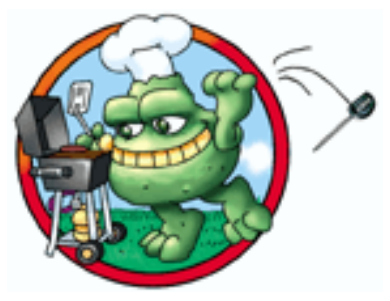

Food and Drug Administration: http://vm.cfsan.fda.gov/ dms/seniors.html (Seguridad alimenticia para adultos mayores, material disponible en inglés y en español)

\section{Manejo y Reducción de Riesgo en Enfermedades}

National Diabetes Education Program:

http://ndep.nih.gov

(Prevención, tratamiento e investigación; materiales disponibles en inglés y español)

National Heart, Lung and Blood Institute: http://www.nhlbi.nih.gov

(Alta presión arterial, colesterol, problemas de sueño, recetas saludables y mas)

The National Osteoporosis Foundation: http://www.nof.org

(Prevención, tratamiento e investigación)

Ediciones para adultos mayores: Todos estos sitios Web proveen un gran rango de información y servicios de interés para adultos maduros.

Departamento de asuntos para adultos de la Florida:

http://elderaffairs.state.fl.us

Instituto Nacional de Envejecimiento: http://www.nih.gov/nia

Administración de Alimentos y Medicinas

http://vm.cfsan.fda.gov/ /rd/advice.html

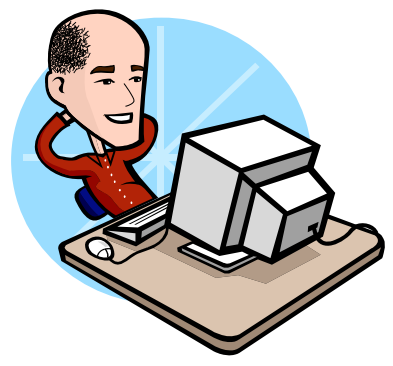

FirstGov para adultos mayores: http://www.firstgov.gov/Topics/Seniors.shtml

Administración de Envejecimiento: http://www.aoa.gov

Para ver si los programas que le interesan a usted están siendo ofrecidos en su condado, llame a su oficina de Extensión del condado. Busque en las páginas azules de su guía telefónica para conseguir el número. En la Florida usted puede encontrar su oficina por Internet: http://solutionsforyourlife.ufl.edu/map/index.html. 